\title{
Ankylosis progressive homolog upregulation inhibits cell viability and mineralization during fibroblast ossification by regulating the Wnt/ $\beta$-catenin signaling pathway
}

\author{
XINDONG HE and YONGQIANG DONG \\ Department of Spinal Surgery, The People's Hospital of Xinchang, Xinchang, Zhejiang 312500, P.R. China
}

Received December 16, 2019; Accepted July 13, 2020

DOI: $10.3892 / \mathrm{mmr} .2020 .11576$

\begin{abstract}
Ankylosis progressive homolog (ANKH) is associated with fibroblast ossification in ankylosing spondylitis (AS). As the human ANKH gene is poorly characterized relative to its murine counterpart, the aim of the present study was to examine ANKH expression in ligament tissue isolated from patients with AS and the role played by this gene in AS-associated fibroblast ossification. Fibroblasts were isolated from ligament tissue collected from patients with AS and ligament tissue from individuals with spinal cord fractures, then cultured. Fibroblasts from patients with AS were subsequently transfected with an ANKH overexpression vector, while those collected from individuals with spinal cord fractures were transfected with small interfering RNA specific for ANKH. Cell viability, apoptosis and mineralization were analyzed using MTT assays, flow cytometry and Alizarin Red staining, respectively. Furthermore, ANKH mRNA and protein expression levels were analyzed using reverse transcription-quantitative PCR and western blotting analysis, respectively. The expression levels of osteogenesis markers, including alkaline phosphatase, osteocalcin, Runt-related transcription factor 2, c-Myc, as well as the $\beta$-catenin signaling protein, were also determined using western blotting. The results of the present study revealed that ANKH protein expression levels were downregulated in AS total ligament tissue extract, compared with spinal fracture ligament. Moreover, the fibroblasts derived from patients with AS exhibited an increased viability and reduced apoptosis
\end{abstract}

Correspondence to: Dr Yongqiang Dong, Department of Spinal Surgery, The People's Hospital of Xinchang, 117 Middle Gushan Road, Nanming Street, Xinchang, Zhejiang 312500, P.R. China E-mail: dongyq_yongqd@163.com

Abbreviations: ANKH, ankylosis progressive homolog; AS, ankylosing spondylitis; ALP, alkaline phosphatase; OCN, osteocalcin; Runx2, Runt-related transcription factor 2; RT-qPCR, reverse transcriptionquantitative PCR

Key words: ankylosing spondylitis, ankylosis progressive homolog, fibroblast, ossification, Wnt//-catenin signaling pathway rates, compared with the fibroblasts from patients with spinal fracture. Notably, ANKH overexpression inhibited viability, mineralization and ossification, increased the phosphorylation of $\beta$-catenin and downregulated $\beta$-catenin and c-Myc protein expression levels in fibroblasts from patients with AS. In addition, ANKH overexpression increased the ratio of $\mathrm{p}-\beta$-catenin $/ \beta$-catenin in fibroblasts from patients with AS. By contrast, ANKH silencing in fibroblasts from patients with spinal fracture resulted in the opposite effect. In conclusion, the findings of the present study suggested that ANKH may inhibit fibroblast viability, mineralization and ossification, possibly by regulating the $\mathrm{Wnt} / \beta$-catenin signaling pathway.

\section{Introduction}

The chronic progression of ankylosing spondylitis (AS) is characterized by inflammatory bone erosion, intravertebral bone loss and abnormal bone overgrowth $(1,2)$. Sacroiliac joints, the vertebral column and ligaments affected by inflammation have been discovered to gradually cause extensive bone generation, leading to stiffness and fusion of the spine and syndesmophyte formation (3). Although previous studies have examined genetic and environmental factors, sex, age and ethnicity as causative factors, to the best of our knowledge, the etiology of AS remains unclear (3-5). Genetic factors underlying AS pathogenesis have been widely studied (6-8), and several genes that have been identified as susceptibility factors of AS may support the diagnosis of AS, such as HLA-B27, HLA-B51 and $\operatorname{ERAP1}(5,9,10)$. In addition, genetic associations with AS may also provide insight into the etiopathogenesis of this disease (11). Although the molecular functions of several genes have been studied in the context of AS, their potential pathogenic role and their possible therapeutic use have not been evaluated (12).

Ankylosis progressive homolog (ANKH), an amino acid of 492 base pairs in length, is a multichannel transmembrane protein that transports intracellular pyrophosphate (PPi) to the extracellular milieu (13). Extracellular PPi was discovered to be a regulator of pathological calcification and a potential inhibitor of calcium phosphate mineralization (14-16). ANKH is the human homolog of the murine ANK gene (15). It has been demonstrated that the loss of ANK transporter function in mice led to excessive mineralization due to reduced PPi transport $(17)$, which was later confirmed by other studies $(18,19)$. 
Gurley et al (18) illustrated the role of ANK in PPi transport and suggested that ANKH mutations may cause skeletal diseases in humans. Ho et al (19) reported that ANK-deficient mice displayed increased PPi levels and presented with mineralization and skeletal ankylosis resembling AS. Thus, these previous studies indicated that ANK may regulate ectopic mineralization in animal models.

AS is characterized by pathological osteogenesis (20). Previous studies suggested that fibroblasts may be the target of heterotopic ossification because these cells belong to the same lineage as osteoblasts and were discovered to express osteogenesis-related genes, such as BMP2, osteocalcin and Runx2 $(21,22)$. Fibroblasts are resident cells that preserve the extracellular matrix, both in healthy conditions and during inflammation (23). Thus, fibroblasts were suggested as likely contenders to be involved in osteogenesis (24). Fibroblasts and osteoblasts both originate from mesenchymal stem cell with overlapping phenotypes and through similar differentiation pathways, allowing fibroblasts to differentiate into osteoblasts and osteoblasts to differentiate into fibroblasts (25). In addition, the proliferative and osteogenic potential of fibroblasts was discovered to increase following the stimulation with fibronectin or BMP2 $(26,27)$. Therefore, fibroblasts may serve as important mediators of osteogenesis.

The aim of the present study was to determine the function of ANKH in fibroblasts isolated from patients with AS. ANKH expression levels were analyzed in ligament tissue collected from patients with AS, and explored the effect of ANKH on the fibroblast cell viability, mineralization and ossification differentiation. From the results, it was hypothesized that the regulation of ANKH may affect fibroblast cell mineralization and ossification in AS.

\section{Materials and methods}

Patients and tissue samples. Ligament tissue samples were collected from four patients with AS (male; age, 18-42) and four patients with spinal fracture (JK) (male; age, 22-44) who attended The People's Hospital of Xinchang Hospital in March 2019 for treatment, according to the modified New York criteria (28). The patients used nonsteroidal anti-inflammatory drugs or disease-modifying anti-rheumatic drugs, but not anti-tumor necrosis factor. Written informed consent forms were signed by all patients. The study was approved by The Ethics Committees of the People's Hospital of Xinchang (Xinchang, China; approval no. XC201902114).

Cell culture. The ligaments samples from patients with AS and JK were separated in 60-mm sterile Petri dishes, and washed three times with D-Hank's balanced salt solution (HBSS; cat. no. 14170161; Gibco; Thermo Fisher Scientific, Inc.). The tissues were then sectioned into $1-3-\mathrm{mm}^{3}$ blocks and washed with HBSS twice. The blocks were maintained in a $25-\mathrm{cm}^{2}$ culture flask, with $4 \mathrm{~mm}$ space in between tissue blocks. Next, 2 ml high-glucose DMEM (cat. no. 11965118; Gibco; Thermo Fisher Scientific, Inc.) supplemented with 10\% FBS (cat. no. A3160901; Gibco; Thermo Fisher Scientific, Inc.) was added to the flask. The flask was placed vertically inside an incubator at $37^{\circ} \mathrm{C}$ with $5 \% \mathrm{CO}_{2}$ for $4 \mathrm{~h}$. The bottle was gently laid flat at the end of this incubation, and the medium was changed every three days thereafter. After 4-8 days, when the cells reached $80 \%$ confluence, they were washed with HBSS and added to $1 \mathrm{ml} 0.25 \%$ trypsin solution (cat. no. R001100; Gibco; Thermo Fisher Scientific, Inc.) at $37^{\circ} \mathrm{C}$. After $2 \mathrm{~min}, 3 \mathrm{ml}$ DMEM supplemented with $100 \mathrm{U} / \mathrm{ml}$ penicillin, $100 \mathrm{mg} / \mathrm{ml}$ streptomycin and 10\% FBS was immediately added to terminate cell dissociation. The cells were collected and centrifuged in a $15-\mathrm{ml}$ centrifuge tube at $1,000 \mathrm{x}$ g for $5 \mathrm{~min}$ at $4^{\circ} \mathrm{C}$. The cell suspension was then divided (1:2) for secondary culture at $37^{\circ} \mathrm{C}$ with $5 \% \mathrm{CO}_{2}$. The medium was changed every two days, and the cells were further subcultured in an incubator at $37^{\circ} \mathrm{C}$ with $5 \% \mathrm{CO}_{2}$ whenever confluence reached $80-90 \%$. Cells in the third generation were used for experimentation following examination of cell morphology under an inverted phase-contrast microscope (magnification, $x 100$; Chongqing UOP Photoelectric Technology Co., Ltd.).

Immunocytochemistry. Immunocytochemistry was performed to analyze the expression levels of vimentin in fibroblasts isolated from patients with AS and JK. Slides covered with fibroblast cells were washed with PBS three times for 5 min each time. After washing, 4\% paraformaldehyde was added to each slide for $15 \mathrm{~min}$ at room temperature for fixed slides. Excess amounts of paraformaldehyde was removed, and the slices were then washed again with PBS three times for 5 min each time. Subsequently, $0.03 \%$ Triton $\mathrm{X}-100$ was added to the slides for $25 \mathrm{~min}$ at room temperature and further incubated with $3 \% \mathrm{H}_{2} \mathrm{O}_{2}$ for $10 \mathrm{~min}$ at room temperature. After blocking with $2 \%$ BSA (cat. no. 11021037; Gibco; Thermo Fisher Scientific, Inc.) for $30 \mathrm{~min}$ at room temperature. After washing with PBS three times for 5 min each time, the slides were then incubated with $50 \mu 1$ anti-vimentin antibody (1:200; cat. no. ab193555; Abcam) overnight at $4^{\circ} \mathrm{C}$. Following the primary antibody incubation, the slides were washed with PBS three times for 5 min each time, then incubated with $50 \mu$ l goat anti-rabbit IgG H\&L (DyLight ${ }^{\circledR} 488$ ) preabsorbed secondary antibody (1:100; cat. no. ab96899; Abcam) for $30 \mathrm{~min}$ at $37^{\circ} \mathrm{C}$ and then washed again with PBS three times. Staining was then visualized using a DAB staining kit (cat. no. E670033; Sangon Biotech Co., Ltd.) for 3-5 min at room temperature, and the slides were examined under an inverted phase-contrast microscope (magnification, $\mathrm{x} 400$ ).

Cell transfection. The ANKH-pCMV6-XL5 overexpression plasmid (cat. no. SC120218) and empty vector negative control (NC; cat. no. PCMV6XL5) were purchased from OriGene Technologies, Inc. Fibroblasts from patients with AS were transfected with ANKH overexpression vector or NC. Fibroblasts from patients with JK were transfected with small interfering RNA (si) specific for ANKH (siANKH) or siNC, siANKH (5'-UCACUAUAAGCUAUCAGUGUG-3') and siNC (5'-UUCUCCGAACGUGUCACGU-3') were obtained from Guangzhou RiboBio Co., Ltd.

Fibroblasts were seeded into 24-well culture plates at a density of $2 \times 10^{4}$ cells/well one day before transfection and cultured to $90 \%$ confluence in $0.5 \mathrm{ml}$ medium with $10 \%$ FBS without antibiotics. On the day of transfection, $20 \mathrm{pmol}$ siANKH/siNC, or $2 \mu \mathrm{g}$ ANKH/NC were separately diluted 
in $50 \mu 1$ DMEM (cat. no. 12491015; Gibco; Thermo Fisher Scientific, Inc.). A volume of $1 \mu$ l Lipofectamine ${ }^{\circledR} 2000$ (cat. no. 11668019; Invitrogen; Thermo Fisher Scientific, Inc.) was separately diluted in $50 \mu 1 \mathrm{DMEM}$ and incubated at room temperature for $5 \mathrm{~min}$. The diluted siANKH, siNC, ANKH or NC was then mixed with diluted Lipofectamine ${ }^{\circledR} 2000$ and placed at room temperature for $20 \mathrm{~min}$, then added to the cells. Finally, the cells were incubated at $37^{\circ} \mathrm{C}$ with $5 \% \mathrm{CO}_{2}$ for $48 \mathrm{~h}$, then harvested for subsequent experimentation. Untransfected cells also served as an additional control group.

Cell viability assay. Fibroblasts from patients with AS or JK were seeded into 96-well culture plates at $200 \mu \mathrm{l}$ per well, then incubated for 1-6 days. Following the incubation, an MTT assay was used to detect cell viability. Briefly, $20 \mu 1$ MTT (5 mg/ml; cat. no. M6494; Invitrogen; Thermo Fisher Scientific, Inc.) was added to the cells for $4 \mathrm{~h}$ at $37^{\circ} \mathrm{C}$. After discarding the supernatant, $100 \mu \mathrm{l}$ DMSO (cat. no. D12345; Invitrogen; Thermo Fisher Scientific, Inc.) was added to each well to dissolve the formazan crystals. The absorbance was measured at $490 \mathrm{~nm}$ at the initial timepoint, then every day over a time course of 6 days using a microplate reader. In a separate experiment, absorbance was read at 24, 48 and $72 \mathrm{~h}$ following transfection; the rest of the experimental details were unchanged.

Flow cytometric analysis of apoptosis. Apoptosis was analyzed using an Annexin V-FITC/propidium iodide (PI) staining kit (cat. no. V13242; Invitrogen; Thermo Fisher Scientific, Inc.). Fibroblasts $\left(2 \times 10^{5}\right.$ cells/well $)$ were cultured in 6 -well plates for $24 \mathrm{~h}$ at $37^{\circ} \mathrm{C}$, then washed with cold PBS and centrifuged at $1,000 \mathrm{x} \mathrm{g}\left(5 \mathrm{~min}, 4^{\circ} \mathrm{C}\right)$. The cells were subsequently resuspended in $1 \mathrm{X}$ Annexin binding buffer, $5 \mu \mathrm{l}$ Annexin V-FITC and $5 \mu \mathrm{l}$ PI was added to the cells. The cells were incubated at room temperature for $15 \mathrm{~min}$, then added to $400 \mu \mathrm{l} 1 \mathrm{X}$ Annexin binding buffer. Cell apoptosis was assessed by flow cytometry using a FACScan instrument (BD Biosciences) equipped with CellQuest software (version 5.1; BD Biosciences). The apoptosis rate was calculated as the sum of early-apoptotic and late-apoptotic ell frequencies. Unstained cells, as well as Annexin V and PI single-stained cells were used as controls, and the gates for positive staining were set according to these controls.

Reverse transcription-quantitative PCR (RT-qPCR). Relative ANKH mRNA expression levels were analyzed using RT-qPCR. Briefly, total RNA was extracted from fibroblasts using TRIzol ${ }^{\circledR}$ reagent (cat. no. 15596018; Invitrogen; Thermo Fisher Scientific, Inc.). RNA concentration was measured using a NanoDrop ${ }^{\mathrm{TM}} 8000$ spectrophotometer (Thermo Fisher Scientific, Inc.). In addition, RNA integrity was confirmed by visualization of the fragments in $1.5 \%$ agarose gel electrophoresis (Invitrogen; Thermo Fisher Scientific, Inc.) followed by ethidium bromide and visualized under ultraviolet light.

RT into cDNA was performed using a PrimeScript RT Reagent kit with gDNA Eraser (cat. no. RR047A; Clontech Laboratories, Inc.). Briefly, $7 \mu \mathrm{l}$ RNA, $1 \mu \mathrm{l}$ gDNA Eraser and $2 \mu 15 \mathrm{X}$ gDNA Eraser buffer were added into a reaction
Table I. Primer sequences used for reverse transcription-quantitative PCR.

Gene $\quad$ Primer sequence $\left(5^{\prime} \rightarrow 3^{\prime}\right)$

Ankylosis progressive F: GTGGGCCTGGTGTTTGTGAA homolog

GAPDH

R: CCTTCTCGTCTTGCTCCCC

F: TGGATTTGGACGCATTGGTC

R:TTTGCACTGGTACGTGTTGAT

F, forward; R, reverse.

tube and incubated at $42^{\circ} \mathrm{C}$ for $2 \mathrm{~min}$. The $10 \mu \mathrm{l}$ sample was then mixed with $1 \mu \mathrm{l}$ PrimeScript RT enzyme mix I, $1 \mu \mathrm{l}$ RT primer mix, $4 \mu 1$ 5X PrimeScript buffer II and $4 \mu 1$ RNase-free distilled water. All samples were incubated at $37^{\circ} \mathrm{C}$ for $15 \mathrm{~min}$ and at $85^{\circ} \mathrm{C}$ for $5 \mathrm{sec}$, then allowed to cool down on ice. The resulting cDNA concentration and OD values were measured on a NanoDrop 8000 spectrophotometer. RT-qPCR was subsequently performed using a 7500 Real-Time PCR system (cat. no. 4351105; Applied Biosystems; Thermo Fisher Scientific, Inc.) with SYBR ${ }^{\circledR}$ Green PCR Master Mix (4312704, Thermo Fisher Scientific, Inc.). The thermocycling conditions consisted of an initial denaturation at $95^{\circ} \mathrm{C}$ for $10 \mathrm{~min}$ followed by 40 cycles at $94^{\circ} \mathrm{C}$ for $5 \mathrm{sec}$ and $60^{\circ} \mathrm{C}$ for $1 \mathrm{~min}$. The experiment was carried out three times. The relative expression levels of the mRNA was analyzed using the $2^{-\Delta \Delta \mathrm{Cq}}$ method (29), and ANKH expression was normalized to GAPDH. All primers used in in the present study were purchased from Sangon Biotech Co., Ltd. and the primer sequences are presented in Table I.

Alizarin Red staining. A 0.1\% Alizarin Red dye liquor (pH 8.3) was prepared by dissolving $0.1 \mathrm{~g}$ Alizarin Red powder (cat. no. 130-22-3; Guidechem) in $100 \mathrm{ml}$ Tris-HCl buffer (0.1 mol/1; cat. no. AP-9005-125; Thermo Fisher Scientific, Inc.). Fibroblasts isolated from the ligament tissue of patients with AS or JK $\left(2 \times 10^{4}\right.$ cells/well) were seeded into six-well plates. A cover glass was added to the 6 -well plate before the cells were inoculated. When the cells reached $\sim 50 \%$ confluence, the samples were collected, washed in PBS, then fixed in $4 \%$ methanol for $15 \mathrm{~min}$ at room temperature. The cells were then washed again with PBS three times for 3 min each time. Each cover glass was incubated with $0.1 \%$ Alizarin Red dye liquor for $30 \mathrm{~min}$ at $37^{\circ} \mathrm{C}$, then washed using double steaming water three times for 3 min each time. The slides were examined under an optical microscope (magnification, x400), and Alizarin Red staining absorbance was read at $510 \mathrm{~nm}$ for quantification.

Western blotting. Proteins were extracted from ligament tissue and fibroblast by using RIPA (cat. no. 89900; Thermo Fisher Scientific, Inc.). Protein concentration in the supernatant was measured using a Pierce ${ }^{\mathrm{TM}}$ BCA Protein assay kit (cat.no.23225; Thermo Fisher Scientific, Inc.). A total of 20-40 $\mu \mathrm{g}$ protein lysate was separated by SDS-PAGE on $12 \%$ gels (cat. no. P0012A; Beyotime Institute of Biotechnology), then transferred onto PVDF membranes (cat. no. FFP28; Beyotime Institute of 
Biotechnology). The membranes were subsequently blocked using 5\% non-fat milk in TBS containing $0.1 \%$ Tween 20 (cat. no. TA-999-TT; Thermo Fisher Scientific, Inc.) at room temperature for $1 \mathrm{~h}$. The membranes were then incubated overnight at $4^{\circ} \mathrm{C}$ with the following primary antibodies: Anti-GADPH (cat. no. ab8245; 1:1,000; 36 kDa; Abcam), anti-ANKH (cat. no. ab90104; 1:1,000, 54 kDa; Abcam), anti-alkaline phosphatase (ALP; cat. no. ab83259; 1:1,000, 39 kDa; Abcam), anti-osteocalcin (OCN; cat. no. ab93876; 1:500; $11 \mathrm{kDa}$; Abcam), anti-Runt-related transcription factor 2 (Runx2; cat. no. ab23981; 1:1,000; $60 \mathrm{kDa}$; Abcam), anti-phosphorylated (p)- $\beta$-catenin (cat. no. 9561; 1:1,000, 92 kDa; Cell Signaling Technology, Inc.), anti- $\beta$-catenin (cat.no. 9562; 1:1,000,92 kDa; Cell Signaling Technology, Inc.) and anti-c-Myc (cat. no. ab32072; 1:1,000; 57 kDa; Abcam). Following the primary antibody incubation, the membranes were incubated with a goat anti-rabbit IgG horseradish peroxidase-conjugated secondary antibody (cat. no. ab205718; 1:5,000, $42 \mathrm{kDa}$; Abcam) at room temperature for $1 \mathrm{~h}$. Protein bands were visualized using an enhanced chemiluminescence reagent kit (cat. no. 345818; EMD Millipore). Protein expression levels were analyzed and normalized to GAPDH using ImageJ software (version 1.5, National Institutes of Health).

Statistical analysis. Statistical analysis was performed using SPSS 16.0 software (SPSS, Inc.) and data are presented as the mean \pm SEM of three experiments. An unpaired Student's t-test was used to analyze statistical differences between two groups. Multi-group comparisons were performed using one-way ANOVA followed by a Tukey's post hoc test. $\mathrm{P}<0.05$ was considered to indicate a statistically significant difference.

\section{Results}

ANKH expression levels in ligament tissue from patients with $A S$. The expression levels of ANKH were investigated in ligament tissues collected from patients with AS and JK controls ( $n=4 /$ group) using western blot analysis. The results revealed that ANKH expression levels were significantly downregulated in the AS group compared with the JK group $(\mathrm{P}<0.001$; Fig. 1A and B).

Fibroblast isolation and culture. Fibroblasts from the AS and JK groups were isolated from the ligament and cultured. The majority of the cells were shuttle-shaped and flat, with 2-3 protuberance, displaying the typical characteristics of fibroblasts (Fig. 1C). Notably, there were no observable differences in the morphology between the two groups. The intermediate filament protein vimentin is an important protein in mammalian fibroblasts (30). Fibroblasts from both groups were used for immunocytochemical staining of vimentin; the expression levels of vimentin in the AS and JK groups were positive (Fig. 1D).

Cell viability and apoptosis of fibroblasts. Cell viability and apoptosis were investigated in the fibroblasts from patients with AS and JK controls. The fibroblast viability in the AS group was significantly increased compared with the JK group $(\mathrm{P}<0.05$ at days $1-3 ; \mathrm{P}<0.001$ at days 4-6; Fig. 1E). Moreover, the apoptotic rate, representing both early and late apoptosis, was significantly reduced in fibroblasts from patients with AS compared with the JK group $(\mathrm{P}<0.001 ;$ Fig. $1 \mathrm{~F})$.

ANKH overexpression inhibits AS fibroblast viability, mineralization and ossification. The effect of ANKH on cell viability, mineralization and ossification differentiation in AS was evaluated by transfecting ANKH overexpression vectors into fibroblasts from patients with AS and siANKH into fibroblasts from patients with JK. In the AS group, the relative ANKH mRNA expression levels were significantly upregulated following the transfection with the ANKH overexpression vector compared with the control and NC groups ( $\mathrm{P}<0.001$; Fig. 2A). By contrast, the transfection with siANKH in JK-derived fibroblasts significantly downregulated ANKH expression levels compared with the control and siNC group $(\mathrm{P}<0.001$; Fig. 2B).

An MTT assay was performed to determine cell viability in both groups at 24,48 and $72 \mathrm{~h}$ following transfection. Following transfection with the ANKH overexpression vector, the viability of fibroblasts in the AS group was significantly reduced compared with the control and siNC groups at each time point $(\mathrm{P}<0.05$; Fig. $2 \mathrm{D})$. However, the cell viability in the JK group was significantly increased, particularly 48 and $72 \mathrm{~h}$ after transfection, compared with the control group and the siNC group at each time point $(\mathrm{P}<0.05$; Fig. 2D).

Moreover, Alizarin Red absorbance in ANKH-overexpressing fibroblasts from the AS group was significantly reduced compared with the control and $\mathrm{NC}$ groups $(\mathrm{P}<0.001$; Fig. $2 \mathrm{E}$ and $\mathrm{F})$. In comparison, Alizarin Red absorbance in the ANKH-silenced JK group was significantly increased compared with the siNC and control groups $(\mathrm{P}<0.001$; Fig. 2G and $\mathrm{H})$.

The expression levels of ossification markers were analyzed following transfection using western blotting analysis. ALP, OCN and Runx 2 expression levels were significantly downregulated following ANKH overexpression in AS fibroblasts compared with the control and NC groups $(\mathrm{P}<0.001$; Fig. 3A and B). By contrast, the expression levels of these ossification markers were significantly upregulated following siANKH silencing in JK fibroblasts compared with the control and siNC groups $(\mathrm{P}<0.001$; Fig. $3 \mathrm{C}$ and $\mathrm{D})$.

ANKH overexpression affects the Wnt/ $\beta$-catenin signaling pathway in fibroblasts. The $\mathrm{Wnt} / \beta$-catenin signaling pathway governs the differentiation of ossification and plays an important role in heterotopic ossification $(25,31)$. The overexpression of ANKH significantly promoted $\beta$-catenin phosphorylation, whilst significantly downregulating the expression levels of $\beta$-catenin and c-Myc in AS fibroblasts compared with the control and NC groups $(\mathrm{P}<0.001$; Fig. $3 \mathrm{E}$ and $\mathrm{F})$. However, siANKH significantly upregulated the expression levels of $\beta$-catenin $(\mathrm{P}<0.05)$ and $\mathrm{c}-\mathrm{Myc}(\mathrm{P}<0.001)$, while inhibiting $\beta$-catenin phosphorylation $(\mathrm{P}<0.001)$ compared with the control and siNC groups in JK fibroblasts (Fig. $3 \mathrm{G}$ and $\mathrm{H}$ ). In addition, the $\mathrm{p}-\beta$-catenin/ $\beta$-catenin ratios were significantly increased in the ANKH group compared with the untransfected control and $\mathrm{NC}$ groups in the AS-derived fibroblasts; however, the $p$ - $\beta$-catenin $/ \beta$-catenin ratio was significantly reduced in the siANKH group compared with the untransfected control and siNC groups in JK fibroblasts $(\mathrm{P}<0.001$; Fig. 3I and J). 
A

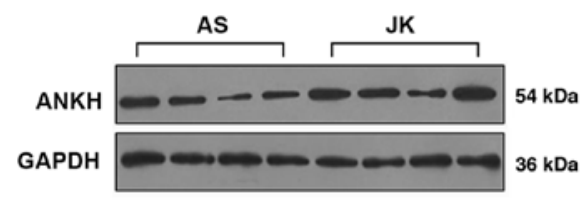

C

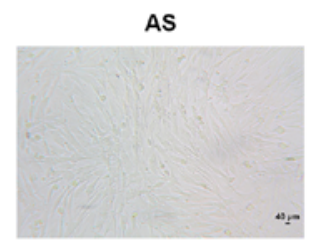

B

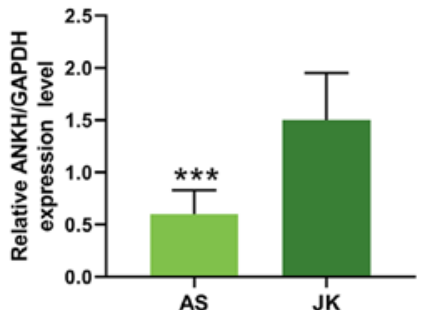

D

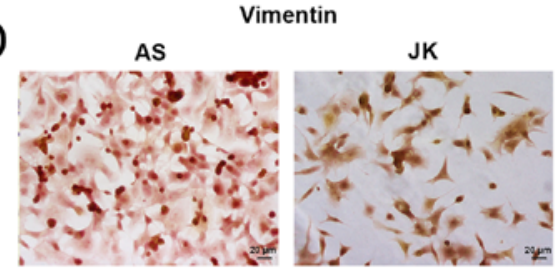

E
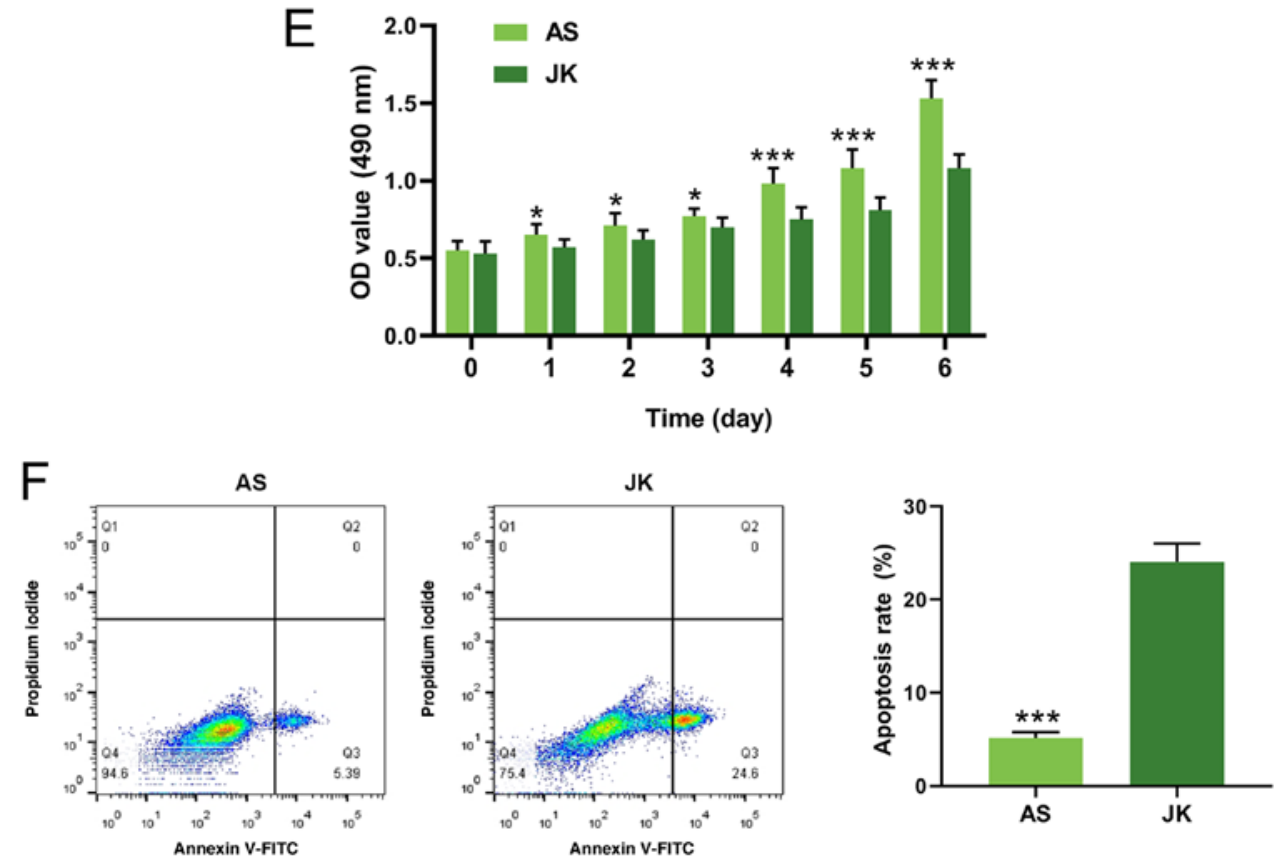

Figure 1. ANKH protein expression levels, cell viability and apoptosis in fibroblasts from patients with AS and JK controls. (A) ANKH protein expression levels in ligament tissue collected from patients with AS and JK controls were analyzed using western blotting. (B) Densitometry data for ANKH expression levels from part (A). Data are presented as the mean \pm SEM. (C) Fibroblasts morphology was examined under a light microscope. Magnification, x100. (D) Immunocytochemistry was performed to analyze vimentin expression levels in AS and JK fibroblasts. Magnification, x400. (E) MTT assays were performed to measure cell viability over a time course of six days. (F) Apoptotic rates of AS or JK fibroblasts were analyzed using flow cytometry. Each dot plot represents necrotic cells $(\mathrm{Q} 1)$, late apoptotic cells (Q2), early apoptotic cells (Q3) and viable cells (Q4). The apoptosis rate (late and early apoptosis) is summarized as a graph on the right-hand side. ${ }^{*} \mathrm{P}<0.05,{ }^{* * *} \mathrm{P}<0.001$ vs. JK. ANKH, ankylosis progressive homolog; AS, ankylosing spondylitis, JK, spinal fracture; OD, optical density; Q, quadrant.

\section{Discussion}

The aim of the present study was to evaluate the role of ANKH in the ossification and mineralization of fibroblasts in patients with AS. The overexpression of the ANKH protein inhibited the viability and mineralization of fibroblasts in patients with AS. However, ANKH silencing led to the opposite effect, indicating a potential anti-osteogenic role for ANKH in AS.

The ANKH gene encodes a multi-channel transmembrane protein, which has a previously characterized role in genetic susceptibility to AS $(32,33)$. A previous study suggested that ANKH did not significantly affect the susceptibility to or clinical manifestations of AS (32), which contradicted the results of another study (33), in which ANKH was associated with genetic susceptibility to AS in a sex-specific manner (33).

Previous studies have also evaluated the role of ANKH in heterotopic ossification $(34,35)$. For instance, Gurley et al (34) demonstrated that the deletion of the ANK gene caused progressive mineralization and joint disease, leading to stiffness of the spine, a symptom similar to AS in humans. Moreover, loss of ANKH function resulted in pathological 
A

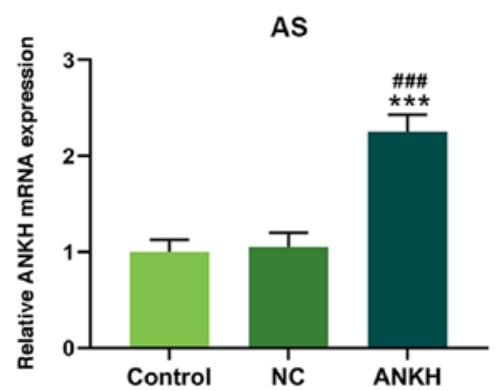

C

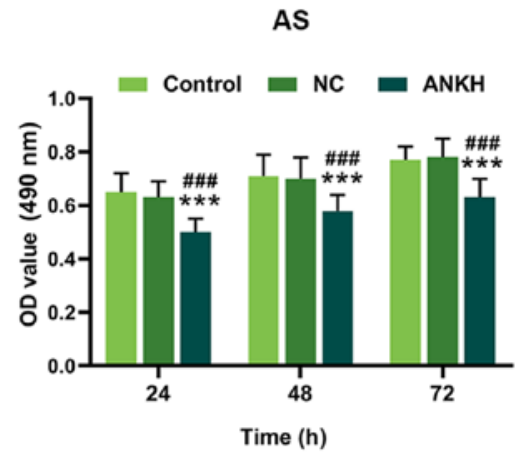

$E$

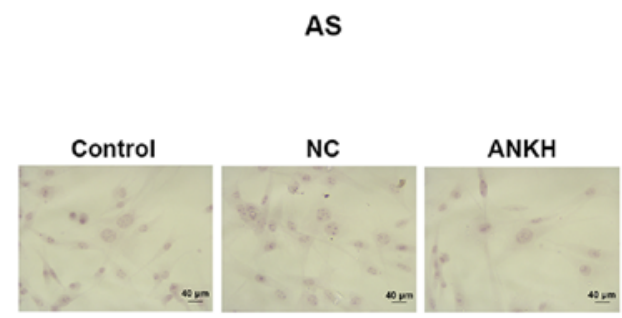

G

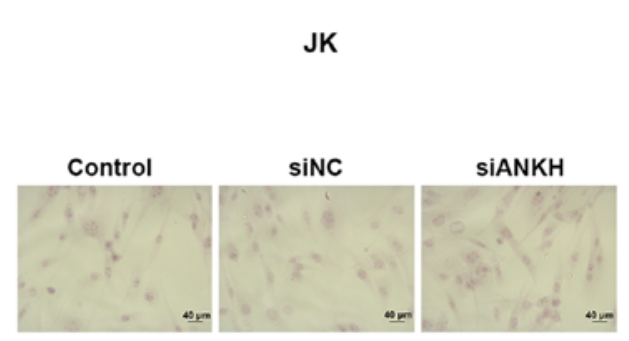

B

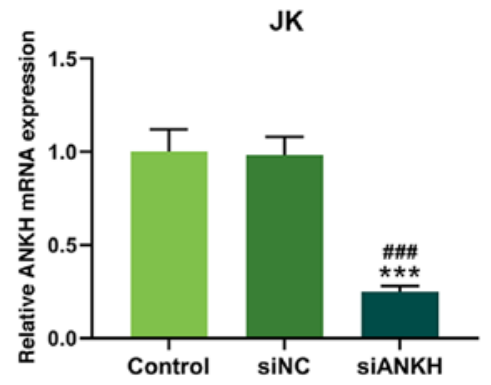

D

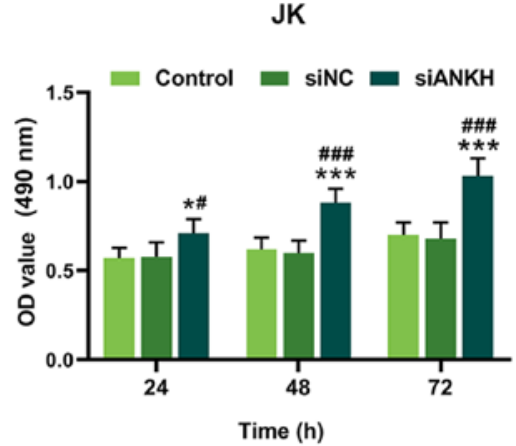

$\mathrm{F}$

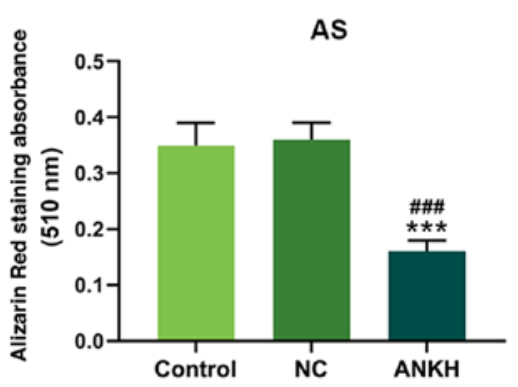

H

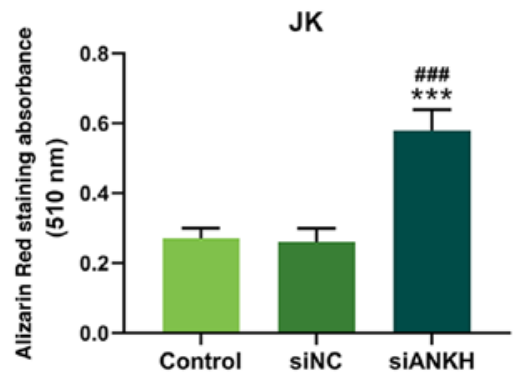

Figure 2. ANKH expression levels affect cell viability and mineralization. ANKH mRNA expression levels in fibroblasts from (A) patients with AS transfected with an ANKH overexpression vector or NC or (B) patients with JK transfected with siANKH or siNC. Cell viability following (C) ANKH overexpression in the AS group and (D) ANKH silencing in the JK group. (E) Mineralization levels were evaluated using Alizarin Red staining in ANKH-overexpressing AS fibroblasts. Magnification, x400. (F) Mineralization levels were semi-quantified in fibroblasts from patients with AS following ANKH overexpression. (G) Mineralization levels were evaluated using Alizarin Red staining following ANKH silencing in JK fibroblasts. Magnification, $\mathrm{x} 400$. (H) Mineralization levels were semi-quantified in fibroblasts from patients with $\mathrm{JK}$ following siANKH transfection. ${ }^{*} \mathrm{P}<0.05,{ }^{* * *} \mathrm{P}<0.001$ vs. control; ${ }^{\#} \mathrm{P}<0.05,{ }^{\# \# \#} \mathrm{P}<0.001$ vs. NC or siNC. ANKH, ankylosis progressive homolog; AS, ankylosing spondylitis, JK, spinal fracture; OD, optical density; si, small interfering RNA; $\mathrm{NC}$, negative control.

hydroxyapatite formation (35). Consistent with these previous studies, the present findings demonstrated that the expression levels of ANKH in ligaments from patients with AS were downregulated compared with the control subjects.

Moreover, the cellular morphology of fibroblasts from patients with AS and control subjects was also examined. Typical fibroblast cellular characteristics and positive vimentin expression confirmed that cultured cells isolated from the ligament retained a fibroblast phenotype. However, fibroblasts from patients with AS displayed increased viability and reduced apoptotic rates compared with the controls, indicating that AS pathogenesis may be related to fibroblast growth. This observation is consistent with a previous study, in which fibroblasts modulated osteoblast metabolism and 
A

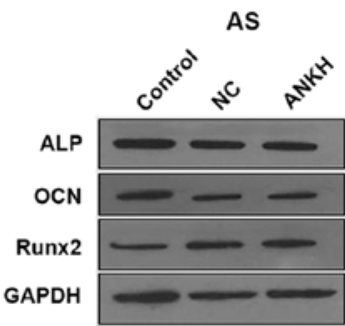

$39 \mathrm{kDa}$

$11 \mathrm{kDa}$

$60 \mathrm{kDa}$

$36 \mathrm{kDa}$

C

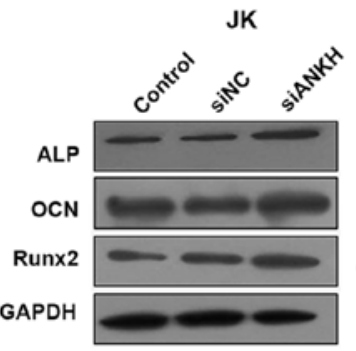

39 kDa

$11 \mathrm{kDa}$

$60 \mathrm{kDa}$

$36 \mathrm{kDa}$

E

AS

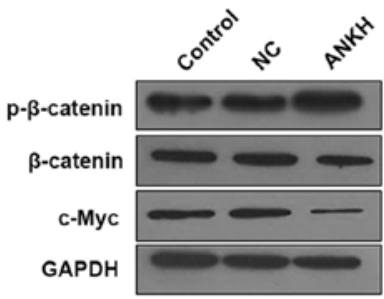

$92 \mathrm{kDa}$

$92 \mathrm{kDa}$

$57 \mathrm{kDa}$

$36 \mathrm{kDa}$

G

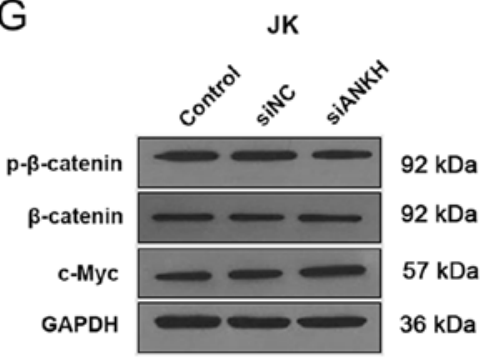

I

AS

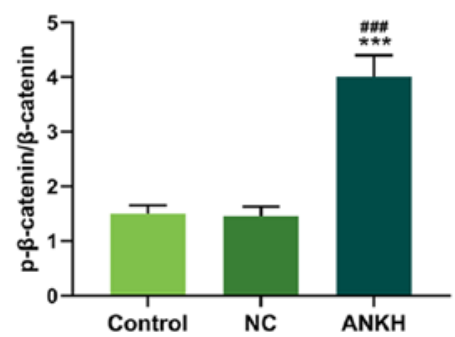

B

AS

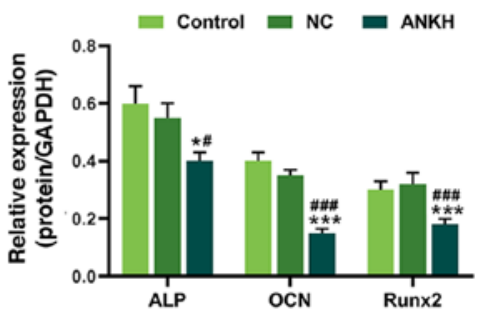

D

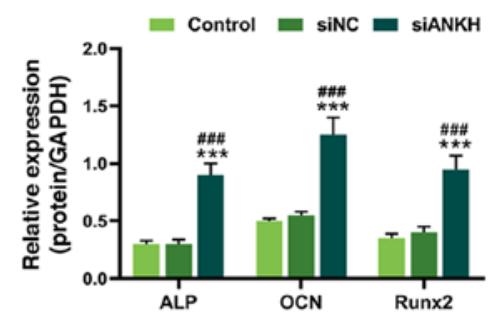

$\mathrm{F}$

AS

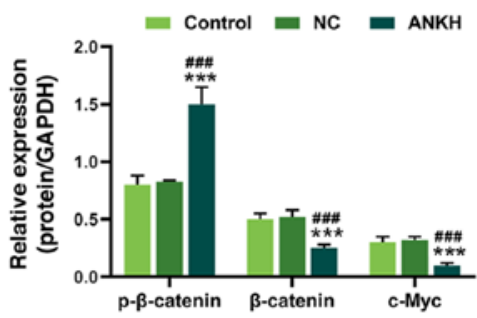

$\mathrm{H}$

JK

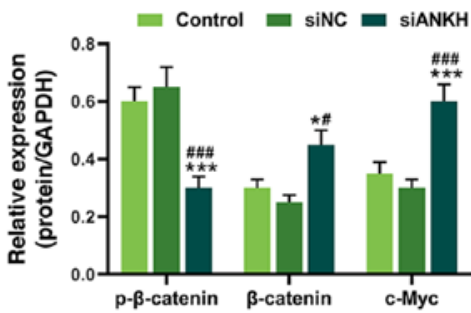

$\mathrm{J}$

JK

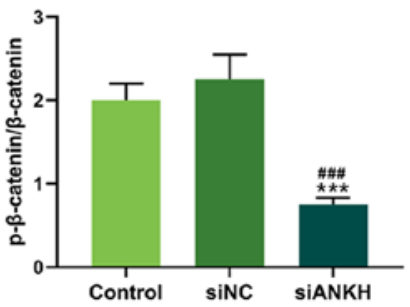

Figure 3. ANKH regulates the expression levels of ossification markers and Wnt signaling-related proteins. (A) Expression levels of ALP, OCN and Runx2 in AS fibroblasts overexpressing ANKH were analyzed using western blotting. (B) Semi-quantification of the expression levels presented in part (A). (C) Expression levels of ALP, OCN and Runx2 in JK fibroblasts transfected with siANKH were analyzed using western blotting. (D) Semi-quantification of the expression levels presented in part (C). Expression levels of $\mathrm{p}-\beta$-catenin, $\beta$-catenin and c-Myc in AS fibroblasts overexpressing ANKH were analyzed using western blotting. (F) Semi-quantification of the expression levels presented in part (E). (G) Expression levels of p- $\beta$-catenin, $\beta$-catenin and c-Myc in JK fibroblasts transfected with siANKH. (H) Semi-quantification of the expression levels presented in part (G). p- $\beta$-catenin: Total $\beta$-catenin expression ratios following (I) ANKH overexpression in AS fibroblasts or (J) ANKH silencing in JK fibroblasts. ${ }^{*} \mathrm{P}<0.05,{ }^{* * *} \mathrm{P}<0.001$ vs. control; ${ }^{\#} \mathrm{P}<0.05,{ }^{\# \# "} \mathrm{P}<0.001$ vs. NC or siNC. ANKH, ankylosis progressive homolog; AS, ankylosing spondylitis, JK, spinal fracture; si, small interfering RNA; NC, negative control; p-, phosphorylated; ALP, alkaline phosphatase; OCN, osteocalcin; Runx2, Runt-related transcription factor 2. 
osteogenesis (24). Therefore, it was hypothesized that inhibiting fibroblast viability or promoting apoptosis may prevent pathological osteogenesis in patients with AS.

In order to investigate the role of $\mathrm{ANKH}$ in fibroblast viability and differentiation, the effects of ANKH overexpression and silencing on fibroblasts were examined. The present findings demonstrated an association between ANKH expression levels and fibroblast viability and mineralization. ANKH overexpression in fibroblasts from patients with AS reduced cell viability and mineralization. Indeed, Alizarin Red staining indicated that the number of mineralized nodules was reduced following ANKH overexpression, suggesting a negative association between ANKH expression levels and fibroblast cell mineralization. Skubutyte et al (36) demonstrated that ANK prevented pathological mineralization. Similarly, Ho et al (19) revealed that the ANK gene prevented mineralization, whereas ANK deficiency accelerated mineralization in joints. Thus, it may be possible to reduce fibroblast mineralization through ANKH overexpression in order to prevent pathological bone formation.

The expression levels of osteogenic markers, such as ALP, OCN and Runx2, were analyzed to determine the levels of osteogenic differentiation and mineralization in fibroblasts from patients with AS. ALP is a phenotypic marker for early-stage osteoblast differentiation that serves a role in bone mineralization (37). In the present study, ANKH overexpression downregulated ALP expression levels in fibroblasts from patients with AS. This result was consistent with a previous study, which demonstrated that ANK was negatively associated with ALP expression levels in bone marrow stromal cells (38). OCN is a marker unique to osteoblasts and a late marker of osteoblast differentiation $(38,39)$. In the present study, the expression levels of OCN and Runx2 were downregulated in ANKH-overexpressing cells. Runx2 can stimulate the transcription of osteoblast-related genes, such as those encoding OPN and OCN (40). Hill et al (41) also demonstrated that ANKH overexpression suppressed the mineralization and ossification of fibroblasts.

Wnt/ $\beta$-catenin signaling induces mesenchymal stem cell differentiation, a precursor of osteoblastic activity (42). Day et al (43) suggested that Runx2 expression levels were possibly regulated by $\beta$-catenin upregulation. Conversely, the inhibition of Wnt signaling was illustrated to impair osteogenic differentiation in another previous study (44). $\beta$-catenin serves an important role in osteocyte viability, differentiation, proliferation and new bone formation $(45,46)$. In fact, during the early and late stages of fracture repair, $\beta$-catenin activation is essential for osteoblast differentiation $(45,46)$, and the loss of $\beta$-catenin resulted in increased bone resorption (47). The present findings were consistent with these aforementioned previous studies. Canonical Wnt/ $\beta$-catenin signaling was reported to stimulate the proliferation and differentiation from fibroblasts to myofibroblast cell (48). In the present study, ANKH silencing reduced $\mathrm{p}-\beta$-catenin expression levels, thereby offering a possible mechanism through which the cell viability and mineralization of normal fibroblasts were stimulated. However, ANKH overexpression in fibroblasts from patients with $\mathrm{AS}$ led to the opposite result. In addition, c-Myc is an important downstream target protein of the Wnt signaling pathway that can regulate proliferation, differentiation and apoptosis (49). Loveridge et al (50) reported that downregulated c-Myc protein levels prevented chondrocyte mineralization. In the present study, a negative association was identified between ANKH and c-Myc expression levels. Indeed, the overexpression of ANKH in fibroblasts from patients with AS downregulated the expression levels of c-Myc, resulting in reduced mineralization, whereas ANKH silencing in normal fibroblasts led to c-Myc upregulation. Thus, ANKH overexpression may reduce mineralization and ossification in AS through c-Myc downregulation and increased $\beta$-catenin phosphorylation and $\mathrm{p}-\beta$-catenin $/ \beta$-catenin, thereby inhibiting pathological bone formation.

However, there were some limitations to the present study. The immunofluorescence identification of JK fibroblasts by vimentin is also required. In addition, the positive effects of ANKH on AS fibroblasts was only determined in vitro; thus, the present findings should be further validated in vivo. Moreover, the potential use of the ANKH gene in clinical treatment also requires validation. Finally, although this preliminary study suggested that ANKH may regulate the Wnt/ $\beta$-catenin pathway to inhibit the viability, mineralization and ossification of fibroblasts, the regulatory mechanism underlying this pathway requires further investigation.

In conclusion, the findings of the present study revealed the role of ANKH in fibroblasts isolated from the ligaments of patients with AS. The results discovered that ANKH expression levels were downregulated in ligaments of patients with AS. Moreover, fibroblasts from patients with AS displayed increased cell viability and reduced levels of apoptosis. ANKH overexpression was discovered to inhibit cell mineralization and ossification, which was likely mediated through its effect on ossification markers and the $\mathrm{Wnt} / \beta$-catenin signaling pathway. Therefore, these results suggested that ANKH overexpression may prevent or delay new bone formation in AS.

\section{Acknowledgements}

Not applicable.

\section{Funding}

No funding was received.

\section{Availability of data and materials}

The datasets used and/or analyzed during the current study are available from the corresponding author on reasonable request.

\section{Authors' contributions}

XH designed the study. XH and YD acquired, analyzed and interpreted the data, drafted the manuscript and critically revised it for important intellectual content. XH and YD authors agree to be accountable for all aspects of the work in ensuring that questions related to the accuracy or integrity of the work are appropriately investigated and resolved. All authors read and approved the final manuscript. 


\section{Ethics approval and consent to participate}

The present study was approved by The Ethics Committees of The People's Hospital of Xinchang (approval no. XC201902114). All procedures involving human participants were in accordance with the 1964 Declaration of Helsinki and its later amendments or comparable ethical standards. Written informed consent was provided by all patients.

\section{Patient consent for publication}

Not applicable.

\section{Competing interests}

The authors declare that they have no competing interests.

\section{References}

1. Smith JA: Update on ankylosing spondylitis: Current concepts in pathogenesis. Curr Allergy Asthma Rep 15: 489, 2015.

2. Leone A, Marino M, Dell'Atti C, Zecchi V, Magarelli N and Colosimo C: Spinal fractures in patients with ankylosing spondylitis. Rheumatol Int 36: 1335-1346, 2016.

3. Woodward LJ and Kam PC: Ankylosing spondylitis: Recent developments and anaesthetic implications. Anaesthesia 64 540-548, 2009

4. Brown MA and Wordsworth BP: Genetics in ankylosing spondylitis-current state of the art and translation into clinica outcomes. Best Pract Res Clin Rheumatol 31: 763-776, 2017.

5. Hanson A and Brown MA: Genetics and the causes of ankylosing spondylitis. Rheum Dis Clin North Am 43: 401-414, 2017.

6. Chen S, Li Y, Deng C, Li J, Wen X, Wu Z, Hu C, Zhang S, Li P, Zhang X, et al: The associations between PD-1, CTLA-4 gene polymorphisms and susceptibility to ankylosing spondylitis: A meta-analysis and systemic review. Rheumatol Int 36: 33-44, 2016

7. Karami J, Mahmoudi M, Amirzargar A, Gharshasbi M, Jamshidi A, Aslani S and Nicknam MH: Promoter hypermethylation of BCL11B gene correlates with downregulation of gene transcription in ankylosing spondylitis patients. Genes Immun 18: 170-175, 2017.

8. Zhang P, Li Q, Qi J, Lv Q, Zheng X, Wu X and Gu J: Association between vitamin $\mathrm{D}$ receptor gene polymorphism and ankylosing spondylitis in Han Chinese. Int J Rheum Dis 20: 1510-1516, 2017.

9. Golder V and Schachna L: Ankylosing spondylitis: An update. Aust Fam Physician 42: 780-784, 2013.

10. Wellcome Trust Case Control Consortium; Australo-AngloAmerican Spondylitis Consortium (TASC); Burton PR Clayton DG, Cardon LR, Craddock N, Deloukas P, Duncanson A, Kwiatkowski DP, McCarthy MI, et al: Association scan of 14,500 nonsynonymous SNPs in four diseases identifies autoimmunity variants. Nat Genet 39: 1329-1337, 2007.

11. Brown MA, Kenna T and Wordsworth BP: Genetics of ankylosing spondylitis-insights into pathogenesis. Nat Rev Rheumatol 12 : 81-91, 2016.

12. Ranganathan V, Gracey E, Brown MA, Inman RD and Haroon N: Pathogenesis of ankylosing spondylitis-recent advances and future directions. Nat Rev Rheumatol 13: 359-367, 2017.

13. Kirsch T, Kim HJ and Winkles JA: Progressive ankylosis gene (ank) regulates osteoblast differentiation. Cells Tissues Organs 189: 158-162, 2009.

14. Kanaujiya J,Bastow E, Luxmi R,Hao Z,Zattas D, Hochstrasser M, Reichenberger EJ and Chen IP: Rapid degradation of progressive ankylosis protein (ANKH) in craniometaphyseal dysplasia. Sci Rep 8: 15710, 2018.

15. Mitton-Fitzgerald E, Gohr CM, Bettendorf B and Rosenthal AK: The role of ANK in calcium pyrophosphate deposition disease. Curr Rheumatol Rep 18: 25, 2016.

16. Wang W, Xu J, Du B and Kirsch T: Role of the progressive ankylosis gene (ank) in cartilage mineralization. Mol Cell Biol 25: 312-323, 2005

17. Williams CJ: The role of ANKH in pathologic mineralization of cartilage. Curr Opin Rheumatol 28: 145-151, 2016.
18. Gurley KA, Reimer RJ and Kingsley DM: Biochemical and genetic analysis of ANK in arthritis and bone disease. Am J Hum Genet 79: 1017-1029, 2006.

19. Ho AM, Johnson MD and Kingsley DM: Role of the mouse ank gene in control of tissue calcification and arthritis. Science 289: 265-270, 2000

20. Qin X, Jiang T, Liu S, Tan J, Wu H, Zheng L and Zhao J: Effect of metformin on ossification and inflammation of fibroblasts in ankylosing spondylitis: An in vitro study. J Cell Biochem 119: 1074-1082, 2018.

21. Yu F, Cui Y, Zhou X, Zhang X and Han J: Osteogenic differentiation of human ligament fibroblasts induced by conditioned medium of osteoclast-like cells. Biosci Trends 5: 46-51, 2011.

22. Rutherford RB, Moalli M, Franceschi RT, Wang D, Gu K and Krebsbach PH: Bone morphogenetic protein-transduced human fibroblasts convert to osteoblasts and form bone in vivo. Tissue Eng 8: 441-452, 2002.

23. Turner JD, Naylor AJ, Buckley C, Filer A and Tak PP: Fibroblast and osteoblasts in inflammation and bone damage. Adv Exp Med Biol 1060: 37-54, 2018.

24. da Costa Fernandes CJ, do Nascimento AS, da Silva RA and Zambuzzi WF: Fibroblast contributes for osteoblastic phenotype in a MAPK-ERK and sonic hedgehog signaling-independent manner. Mol Cell Biochem 436: 111-117, 2017.

25. Zou YC, Yang XW, Yuan SG, Zhang P, Ye YL and Li YK: Downregulation of dickkopf-1 enhances the proliferation and osteogenic potential of fibroblasts isolated from ankylosing spondylitis patients via the $\mathrm{Wnt} / \beta$-catenin signaling pathway in vitro. Connect Tissue Res 57: 200-211, 2016.

26. Zhang WH, Li XL, Guo Y and Zhang Y: Proliferation and osteogenic activity of fibroblasts induced with fibronectin. Braz J Med Biol Res 50: e6272, 2017

27. Chen F, Bi D, Cao G, Cheng C, Ma S, Liu Y and Cheng K: Bone morphogenetic protein 7-transduced human dermal-derived fibroblast cells differentiate into osteoblasts and form bone in vivo. Connect Tissue Res 59: 223-232, 2018.

28. van der Linden S, Valkenburg HA and Cats A: Evaluation of diagnostic criteria for ankylosing spondylitis. A proposal for modification of the New York criteria. Arthritis Rheum 27: 361-368, 1984.

29. Livak KJ and Schmittgen TD: Analysis of relative gene expression data using real-time quantitative PCR and the 2(-Delta Delta C(T)) method. Methods 25: 402-408, 2001.

30. Turowski P, Myles T, Hemmings BA, Fernandez A and Lamb NJ: Vimentin dephosphorylation by protein phosphatase $2 \mathrm{~A}$ is modulated by the targeting subunit B55. Mol Biol Cell 10: 1997-2015, 1999.

31. Tamamura Y, Otani T, Kanatani N, Koyama E, Kitagaki J, Komori T, Yamada Y, Costantini F, Wakisaka S, Pacifici M, et al: Developmental regulation of Wnt/beta-catenin signals is required for growth plate assembly, cartilage integrity, and endochondral ossification. J Biol Chem 280: 19185-19195, 2005.

32. Timms AE, Zhang Y, Bradbury L, Wordsworth BP and Brown MA: Investigation of the role of ANKH in ankylosing spondylitis. Arthritis Rheum 48: 2898-2902, 2003.

33. Tsui HW, Inman RD, Paterson AD, Reveille JD and Tsui FW: ANKH variants associated with ankylosing spondylitis: gender differences. Arthritis Res Ther 7: R513-R525, 2005.

34. Gurley KA, Chen H, Guenther C, Nguyen ET, Rountree RB Schoor M and Kingsley DM: Mineral formation in joints caused by complete or joint-specific loss of ANK function. J Bone Miner Res 21: 1238-1247, 2006.

35. Pendleton A, Johnson MD, Hughes A, Gurley KA, Ho AM, Doherty M, Dixey J, Gillet P, Loeuille D, McGrath R, et al: Mutations in ANKH cause chondrocalcinosis. Am J Hum Genet 71: 933-940, 2002.

36. Skubutyte R, Markova D, Freeman TA, Anderson DG, Dion AS, Williams CJ, Shapiro IM and Risbud MV: Hypoxia-inducible factor regulation of ANK expression in nucleus pulposus cells: Possible implications in controlling dystrophic mineralization in the intervertebral disc. Arthritis Rheum 62: 2707-2715, 2010.

37. Sharma U, Pal D and Prasad R: Alkaline phosphatase: An overview. Indian J Clin Biochem 29: 269-278, 2014.

38. Minashima T, Quirno M, Lee YJ and Kirsch T: The role of the progressive ankylosis protein (ANK) in adipogenic/osteogenic fate decision of precursor cells. Bone 98: 38-46, 2017.

39. Wei J and Karsenty G: An overview of the metabolic functions of osteocalcin. Rev Endocr Metab Disord 16: 93-98, 2015. 
40. An S, Gao Y and Ling J: Characterization of human periodontal ligament cells cultured on three-dimensional biphasic calcium phosphate scaffolds in the presence and absence of L-ascorbic acid, dexamethasone and $\beta$-glycerophosphate in vitro. Exp Ther Med 10: 1387-1393, 2015.

41. Hill TP, Später D, Taketo MM, Birchmeier W and Hartmann C: Canonical Wnt/beta-catenin signaling prevents osteoblasts from differentiating into chondrocytes. Dev Cell 8: 727-738, 2005.

42. Xu C, Wang J, Zhu T, Shen Y, Tang X, Fang L and Xu Y: Cross-talking between PPAR and WNT signaling and its regulation in mesenchymal stem cell differentiation. Curr Stem Cell Res Ther 11: 247-254, 2016.

43. Day TF, Guo X, Garrett-Beal L and Yang Y: Wnt/beta-catenin signaling in mesenchymal progenitors controls osteoblast and chondrocyte differentiation during vertebrate skeletogenesis. Dev Cell 8: 739-750, 2005.

44. Leucht P, Jiang J, Cheng D, Liu B, Dhamdhere G, Fang MY, Monica SD, Urena JJ, Cole W, Smith LR, et al: Wnt3a reestablishes osteogenic capacity to bone grafts from aged animals. J Bone Joint Surg Am 95: 1278-1288, 2013.

45. Duan $P$ and Bonewald LF: The role of the wnt/ $\beta$-catenin signaling pathway in formation and maintenance of bone and teeth. Int J Biochem Cell Biol 77: 23-29, 2016.

46. Chen Y, Whetstone HC, Lin AC, Nadesan P, Wei Q, Poon R and Alman BA: Beta-catenin signaling plays a disparate role in different phases of fracture repair: Implications for therapy to improve bone healing. PLoS Med 4: e249, 2007.
47. Albers J, Keller J, Baranowsky A, Beil FT, Catala-Lehnen P, Schulze J, Amling M and Schinke T: Canonical Wnt signaling inhibits osteoclastogenesis independent of osteoprotegerin. J Cell Biol 200: 537-549, 2013.

48. Xu L, Cui WH, Zhou WC, Li DL, Li LC, Zhao P, Mo XT, Zhang Z and Gao J: Activation of Wnt/ $\beta$-catenin signalling is required for TGF- $\beta / \mathrm{Smad} 2 / 3$ signalling during myofibroblast proliferation. J Cell Mol Med 21: 1545-1554, 2017.

49. Shi L, Wu YX, Yu JH, Chen X, Luo XJ and Yin YR: Research of the relationship between $\beta$-catenin and c-myc-mediated Wnt pathway and laterally spreading tumors occurrence. Eur Rev Med Pharmacol Sci 21: 252-257, 2017.

50. Loveridge N, Farquharson C, Hesketh JE, Jakowlew SB, Whitehead CC and Thorp BH: The control of chondrocyte differentiation during endochondral bone growth in vivo: Changes in TGF-beta and the proto-oncogene c-myc. J Cell Sci 105: 949-956, 1993. 